\title{
Call for North/South code of research ethics
}

\section{Declan Butler, Paris}

The balance of power in research collaboration between scientists in industrialized and developing countries could be redressed by adopting an international code of ethics, says the head of a French research agency.

Philippe Lazar, president of the Institut de Recherche pour le Développement (IRD), the French national agency for scientific research for development, has drawn up a draft text setting out a series of broad principles (see below), and is talking to the French government about getting it adopted by all French research organizations.

Lazar has informally presented it to several other countries worldwide. Ultimately, an international declaration could be one possibility, he says, though at present the proposals are essentially a list of good intentions and need more work on the details. The declaration would not be legally binding - but nor is the Universal Declaration of Human Rights, Lazar points out, and adoption of a text would focus minds on the issues.

The plan has been welcomed by the scientists, legal and ethical experts, and donor agencies contacted by Nature. But their views differ widely on what its scope should be, and the feasibility of translating it into practice.

A plan to foster scientific cooperation between the industrialized North and the developing South comes at just the right time, says Noëlle Lenoir, a member of France's constitutional court and president of the European Group on Ethics in Science and New Technologies. Genomics, population genetics and medical genetics must be global, she says, hoping that a declaration could narrow the widening technology and research gap.

"I often encounter suspicion among researchers in the South towards pushy potential collaborators from the North -

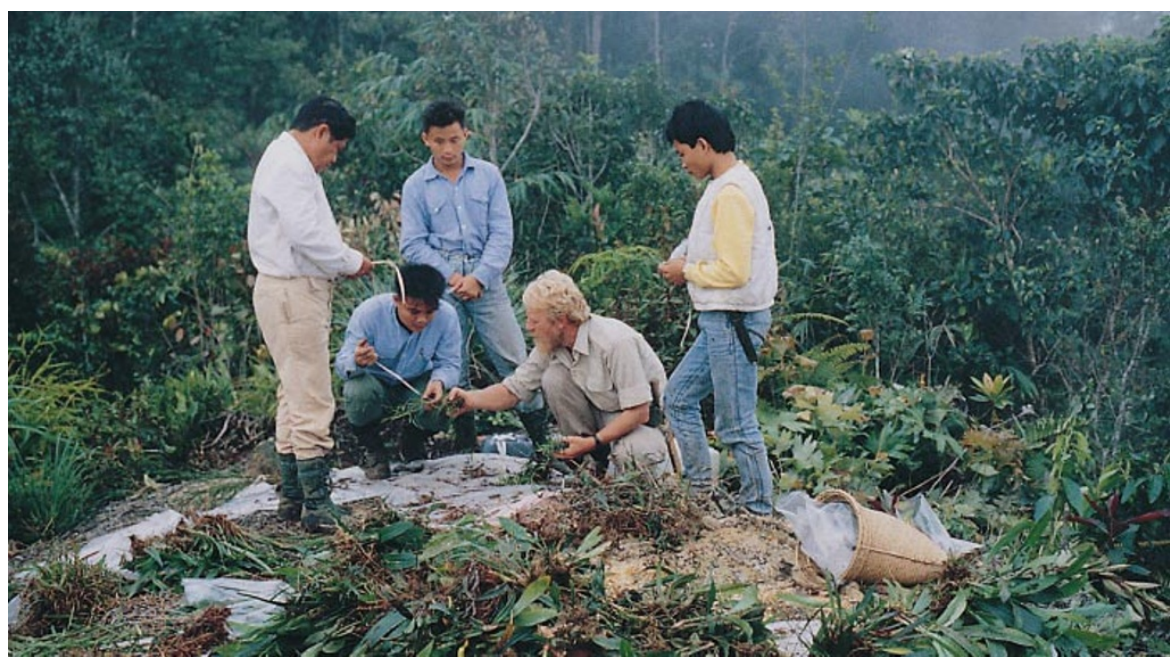

In the clear: the code would protect legitimate specimen collecting, such as this Dutch/Brunei project.

suspicions often held with good reason," says Chris Dye, from the World Health Organization. "If fears of specimen and data poaching, and so on, can be allayed by a new code of professional conduct, so much the better."

Pierre Druilhe, a malaria researcher at the Institut Pasteur in Paris who is usually sceptical of such political initiatives, commends Lazar for taking the initiative. "The concept is good: it's about striking a new deal with developing countries," says Druilhe, who spends much of his time in these parts of the world.

But putting it into practice will be much more difficult, he says: enforcing equal conditions of health and safety at work, for example, would be almost impossible. "The text is not perfect, but if you don't make a start we will never get there."

Others question whether a text singling out North/South issues is the best approach. The text should apply to any research collab-

\section{Main points of the draft declaration}

- No research in a developing country can be done without the participation of teams from that country. - The scientific quality of research conducted in cooperation with developing countries must be the same as that in industrialized countries.

- Northern partners must help train scientific and technical staff in developing countries, and limit the risk of a 'brain drain'.

- Industrialized countries' rules relating to the planning and management of research programmes must be strictly respected in any joint projects. - Each project must undergo systematic ethical examination, taking into account the developing country's culture.

- Health and safety conditions must be the same for everyone involved.

- All participants must be informed about every part of the programme, particularly of any risks and any possible economic or social implications.

- Everyone involved must have right of access to the various methods of publication and be given the chance to maximize the benefit of their results.

- Partners must make a systematic effort to maximize the benefits for the populations and countries involved, without necessarily waiting for official completion.

- No cooperation-based research should be undertaken which, in the present state of knowledge, could be considered potentially harmful to populations, individuals or their environment. - Intellectual property rights on data and results obtained must be shared fairly among the participants, in accordance with their overall contributions. oration, say both Gurinder Shahi, executive director of the Asia-Pacific International Molecular Biology Network, and Lincoln Chen, executive vice-president of the Rockefeller Foundation.

"Scientific, financial and other imbalances in particular associated with rich versus poor countries and their scientists and institutions could be addressed within this overall framework," adds Chen. But he agrees that adoption of guidelines would heighten sensitivity to ethical issues.

Richard Lane, head of international programmes at the UK Wellcome Trust, says the guidelines are novel in their broad scope, but they pay insufficient attention to broader questions such as who benefits from such research, or the fact that local research needs are often very different from those of Northern partners. The guidelines also assume that developing countries have sufficient expertise to negotiate effectively, says Lane, whereas in reality they suffer from an acute lack of research administrators.

"I see the exercise as well-intentioned," says Amir Attaran, from the Center for International Development at Harvard University. His concern is that the present text focuses excessively on the 'how' of research and ignores the bigger question of 'why' — what needs the research is designed to meet.

Attaran says he is disappointed that the text does not address the need for much greater research on the science priorities of the South, such as malaria and countless other neglected tropical diseases.

Lenoir, however, sees a duty in the South too. "Scientific progress in the developing countries is not only a question of cooperation between the North and the South," she says. "It is also an education and ethics issue for developing countries themselves. This should be stressed in any guidelines."

http://www.ird.fr/fr/inst/ird/debat/ 